\title{
ROUTES TO FAILURE AND PREVENTION RECOMMENDATIONS IN WORK SYSTEMS OF HYDROPOWER CONSTRUCTION
}

\author{
Xiazhong ZHENG ${ }^{1}$, Jianlan $\mathrm{ZHOU}^{2}$, Fei WANG ${ }^{1}$, Yang $\mathrm{CHEN}^{2}$ \\ ${ }^{1}$ Hubei Key Laboratory of Construction and Management in Hydropower Engineering, \\ China Three Gorges University, Yichang, China \\ ${ }^{2}$ School of Automation, Huazhong University of Science \& Technology, Wuhan, Hubei, China
}

Received 10 September 2017; accepted 23 March 2018

\begin{abstract}
There are many types of accidents with their own characteristics in hydropower construction. The accidents are mainly results of human errors. It is important to find out the routes to failure and give recommendations pertinently for different accident types. First, 869 accident investigation reports are collected and the human factors are filtered using the Human Factors Analysis and Classification System (HFACS) framework, the norms which link the accident causes and human factors are also explored, the first three accident types are determined by the frequency statistics. The ranking of the factors and the norms of the three accident types is presented using the frequency statistics. The Chi-square, lambda and odds ratios are used to analyze the interdependences between adjacent level factors of three highest frequency accident types. At last, based on the correlation analysis between different human factors, the routes to failure can be determined; containing the norm frequency of factors, the safety recommendations are given to the different accident types pertinently. The results can be auxiliary and effective information for safety managers to conduct scientific and pertinent safety managements.
\end{abstract}

Keywords: human error, work system, inter-rater reliability, correlation analysis, routes to failure, prevention recommendations.

\section{Introduction}

The safety risk of hydropower construction is more significant than the one presented in construction situations, as a result of complex construction environment, large numbers of construction workers, various types of work and various stages of cross-operation and other reasons (Jia et al. 2012; Jiang et al. 2014; Zhou et al. 2014; Liu et al. 2005). Despite the fact that improvements in hydropower construction safety have been made over the last decades, accidents and injuries still occur on construction sites.

Haslam et al. (2005) studied the cases and found that $70 \%$ of the accidents were caused by workers or work teams; Suraji et al. (2001) identified that $88 \%$ of the accidents in construction projects involved unsafe behaviors; they supported the fact that the accidents are mainly results of human errors. Therefore, human error analysis in work systems to explore their root causes is not only an important study of mechanism of the accident occurrence, but also the basis for carrying out a scientific and stand- ardized management of enterprises (Tamborello, Trafton 2017), which has vital significance for safety management of hydropower construction.

One of the earliest studies of human errors is the domino theory of Heinrich (1931). He raised five sequential dominos of accidents causation chain and the second part is the fault of a person. Reason's (Reason 2000) model, which is based on theory of Heimlich, classifies factors of accidents into three domains: organizational/systems, local workplace and unsafe acts. In doing so, the model moves the blame from human errors to the environment in which humans work. HFACS was proposed by Shappell and Wiegmann (2001) and cited by Dekker (2002) as one of the most powerful tools for reconstructing human contributions to various types of accidents. The HFACS system was originally developed as an evaluation framework to analyze and classify operator errors in aviation accidents and mishaps (Shappell, Wiegmann 2001; Wiegmann, Shappell 2003). The advanced version of HFACS

\footnotetext{
*Corresponding author. E-mail: zhoujl1999@163.com,zhou jianlan@hust.edu.cn
} 
based upon Reason's model of latent and active failures has provided an applicable system to investigate human errors in accidents (Madigan et al. 2016).

There are four main levels in the HFACS framework (Daramola 2014; Lenne et al. 2012; Shappell et al. 2007): (1) the unsafe acts tier includes perception errors, decision errors, skill-based errors and violations, the factors of this level result in accidents directly; (2) the preconditions for unsafe acts tier includes technological environment, physical environment, condition of the operator, crew resource management and personal readiness, the factors of this level can result in a unsafe behaviors; (3) the unsafe supervisions tier includes inadequate supervision, planned inappropriate operations, failure to correct known problems and supervisory violations, these factors have a great effect on the condition of unsafe behaviors; (4) the organizational influences tier includes organizational climate, operational process, resource management. For every collected accident, it includes many human errors. These human factors can be filtered from the accident investigation reports and sorting into specific categories based on the HFACS framework (Celik, Cebi 2009; Daramola 2014).

However, the most important function of HFACS framework is to filter the human errors and make a classification of them, which cannot determine the core causations of accidents and relationship of these errors (Zhan et al. 2017). HFACS is only a fundamental framework where these human errors are simply assigned to categories, without the explanations of what contributes to these errors or suggestions of remedies to avoid them in the future. Relatively few published studies with empirical evidence formally describe the independences between human factors by HFACS. Dekker (2001) noted that HFACS framework only can replace human errors by shifting them from the forefront to higher up in the organization instead of finding solutions for them.

Every accident includes two types of errors: active errors and latent errors (Bentley 2009). Active errors result in accidents directly with immediate influences; they are recorded accurately in the accident investigation report (Chiu, Hsieh 2016). Latent errors cause accidents indirectly statistics; their adverse consequences may lie dormant within the system for a long time, only becoming evident combining with other factors to breach the system's defences (Chiu, Hsieh 2016; Madigan et al. 2016), they are also recorded in the accident investigation report after the deep analysis by experts. It is important to analyze the relationship by statistic independence methods using accident investigation report.

Some scholars use statistic independence methods to uncover the relationship between the factors in the HFACS framework, providing evidence to the inter theory of failure to accident behind the framework (Daramola 2014; Lenne et al. 2012; Olsen, Shorrock 2010; Tvaryanas et al. 2006). These analyses begin to describe statistically how actions and decisions at higher managerial levels promulgate down through the organization to result in operational errors and accidents.
However, some of them only concentrated on the correlation analysis without the frequency, and some of them took consideration of correlation and frequency, but frequency belongs to larger categories without segmentation, thus, the results cannot be auxiliary information for making pertinent recommendation. Besides, these analyses concerned on the whole industry without consideration of the characteristics of different accident types.

Hydropower construction involves many types of engineering projects such as dam pouring, external communication facilities (Chen et al. 2017; Koirala et al. 2017). Compared with other industries, the hydropower construction has some special characteristics (Abrams et al. 2017; Moura et al. 2016; Wang, Albert 2017; Zhou et al. 2014), which results in the diversity of accidents and the causes of different accident types are obviously different (Fang et al. 2015). It is not pertinent if we analyze the accidents without considering the distinctions in different types (Bierly et al. 2008). The proposed prevention recommendations have low match ability with the real circumstance. It is important to determine the key human factors of frequently happening accidents and find the routes to failure, the effective recommendations are proposed then.

In consideration of the shortages of the previous studies, we conduct an empirical study to determine the core human factors of different accident types and find the interdependences of factors in HFACS framework and then uncover routes to failure. The remainder of this paper is structured as follows. Section 1 explains the Human Factors Analysis and Classification System and gives the clear descriptions of factors; the analysis methods are also introduced. In Section 2, we use the HFACS framework to filter the human factors of 869 accidents investigation reports collected from hydropower companies. The accident types are classified and the basic statistical regularities are revealed, and the three accident types which have largest number cases are identified. In Section 3, the four most important factors of three largest frequency accident types are determined, the norms rankings of those factors are given using frequency, and the association's strength of different factors in adjacent HFACS level is calculated by the method introduced in Section 1. In Section 4, we discuss the results and give recommendations of different accident types. Finally, we present the conclusion of this study and discuss its limitations. The flowchart of this research is presented in Figure 1.

\section{Methodology}

\subsection{Human error taxonomy}

When we analyze the relationship of factors, the basic data is from the accident investigation reports which should be collected and decomposed to obtain the factors frequency. In the first round, the inter-rater reliability, measured on a category-by-category basis, should be calculated by Cohen's Kappa to assess their consistency. Then, they should reach a consensus in the second round. There are uniform HFACS categories and factors, but there exists 


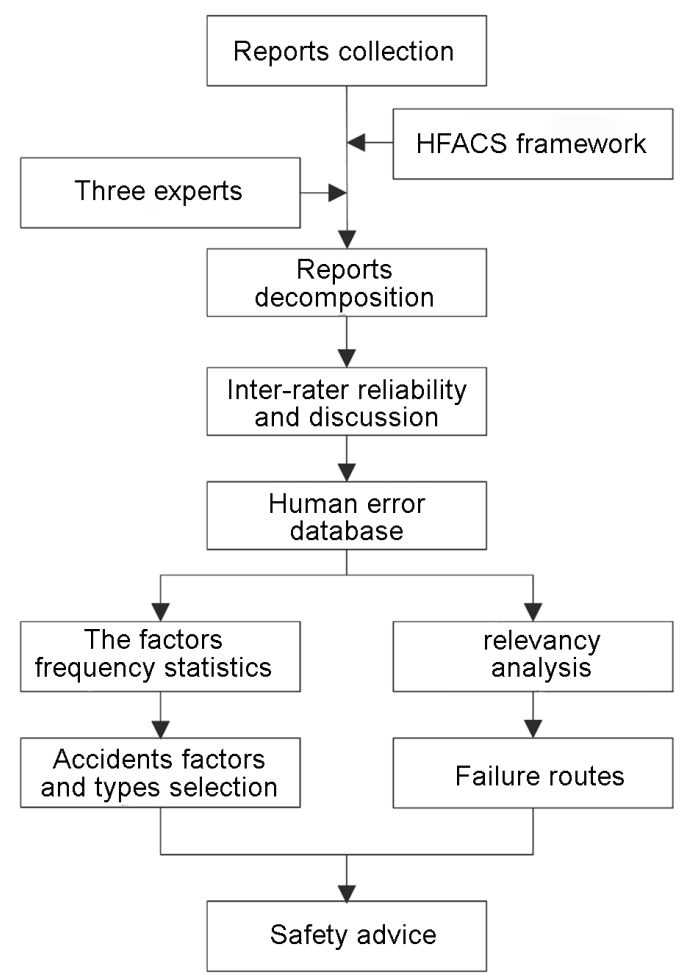

Figure 1. The flowchart of this research

some difference of specific description of each factor. In this study, based on the original HFACS framework and other reference work (Akyuz 2017; Chauvin et al. 2013; Patterson, Shappell 2010; Zhan et al. 2017), construction safety standards, hydropower construction characteristics, the HFACS framework is presented in Table 1.

\subsection{Inter-rater reliability}

We invited three experts to analyze and decompose these accident investigation reports. The basic information of experts is presented in Table 2. In the hydropower construction site, there are a small number of women because of the bad construction conditions and then the three raters happen to be men. Besides this, the raters are selected based on the adequate working experience and suitable academic backgrounds, but other factors like gender and age are not mentioned. Three raters can discuss efficiently and overcome the subjectivity in the limited time. Many scholars also assessed the inter-rate reliability of the HFACS decomposition process with the same principles (Li et al. 2008; Olsen 2014).

The raters finish the accidents decomposition by the HFACS framework, but the use of HFACS framework appears to be straightforward and simple, single rater often complains that they could not confidently classify each error only by taxonomy. This indicates that formal training program (including factors and examples) should be established to ensure that the raters can decompose the accidents rightly. First of all, we use 20 accident reports as example and three raters read them together in threeday seminar to identify all accidents causes' lists. The three raters need to discuss whether results can lead accident or not and they must final reach a consensus if they have any divergence (Ergai et al. 2016). Ensure that raters are proficient in sorting every error until they are able to use HFACS efficiently. At last, the three raters need to classify the all accident causes in accordance with the description for each category independently; every rater has own database and they would get a consensus after discussion in the next month. In this process, they give the result based on the prior experiences. Different rater has different results and in the biases from the truth. Baysari et al. (2009) suggest that inter-rater reliability should be best calculated separately for each rater pair (i.e. rater 1 vs rater 2 , rater 2 vs rater 3 , etc.). In our study, the Kappa values proposed by Cohen (1960) are employed to conduct consistency testing and measure the inter-rater reliability (Zhan et al. 2017; Zhou, Lei 2017).

\subsection{Overview of analysis method rationale}

In every collected accident investigation report, there are four logical relationships between two factors in adjacent levels: both of them occur, neither of them occurs or one of them occurs. The relationships of the two factors are presented in Table 3. After every accident investigation report has been decomposed using HFACS framework, the frequency and marginal frequency of every factor can be calculated. First, the $\chi^{2}$ (Chi-square) (Chen, Y., Chen, M. C. 2011) is used to test for independence, where we assume that represents the hypothesis that human factors of HFACS are independent of each other; states the human factors of HFACS are dependent and correlated to each other:

$$
\chi^{2}=\frac{\left(N_{1}+N_{2}+N_{3}+N_{4}\right)\left(N_{1} \cdot N_{4}-N_{2} \cdot N_{3}\right)^{2}}{\left(N_{1}+N_{2}\right)\left(N_{3}+N_{4}\right)\left(N_{1}+N_{3}\right)\left(N_{2}+N_{4}\right)} .
$$

By calculating the chi-square statistic using the chisquare distribution and appropriate degrees of freedom, the significance level was chosen and obtained (Liu et al. 2017; Masirevic 2017; Roscoe, Byars 1971). When the actual value is greater than the calculated value, we reject the hypothesis and accept, which means that factors are dependent on each other.

However, the $\chi^{2}$ method cannot uncover the real association, and the relationship analysis should be supplemented with another effective method - Goodman and Kruskal's lambda $(\lambda)$. The lambda can be used to calculate the proportional reduction in human error, and it ranges from 0 to 1 when 1 represents certainty. The advantage of Lambda (Goodman, Kruskal 1954) is that it is a directional statistic, which matches the potential influence relationship between the lower (operational) and upper (organizational) levels. In general, the factors in lower levels cannot adversely affect higher levels one. Higher levels in the HFACS are deemed to influence (cause) changes at the lower levels, thus going beyond what may be deemed a simple test of co-occurrence between categories. Thus, the asymmetric form of lambda is chosen: 
Table 1. Brief description of HFACS causal categories

\begin{tabular}{|c|c|c|}
\hline Categories & Factors & Description \\
\hline $\begin{array}{l}\text { Level 4: } \\
\text { Organizational } \\
\text { influences }\end{array}$ & $\begin{array}{l}\text { A1: Organizational climate } \\
\text { A2: Operational process } \\
\text { A3: Resource management }\end{array}$ & $\begin{array}{l}\text { Prevailing atmosphere/vision within the organization including such things as } \\
\text { policies, command structure, and culture. } \\
\text { Formal process by which the vision of an organization is carried out including } \\
\text { operations, procedures, and oversight among others, including safety production } \\
\text { laws, regulations and other standards. } \\
\text { Monetary, and equipment resources necessary to carry out the vision, such as } \\
\text { safety production expenses and industrial injury insurance premium. }\end{array}$ \\
\hline $\begin{array}{l}\text { Level 3: } \\
\text { Unsafe } \\
\text { supervisions }\end{array}$ & $\begin{array}{l}\text { B2: Planned inappropriate } \\
\text { operations } \\
\text { B3: Failed to correct known } \\
\text { problems } \\
\text { B4: Supervisory violations }\end{array}$ & $\begin{array}{l}\text { Negligence of duty, fail to provide guidance of equipment maintenance, fail to } \\
\text { provide skills, safety training and training track qualifications, fail to check the } \\
\text { qualification of the equipment; Safety troubleshooting program with a clear } \\
\text { investigation of the purpose, scope, methods and requirements; Safety oversight } \\
\text { (including all productions and business related sites, environment, personnel, } \\
\text { equipment, facilities and activities) and methods; Hazard identification and } \\
\text { safety evaluation for dangerous facilities or sites; Register and archive identified } \\
\text { major hazards in time; Taking measures to monitor major hazards; Identification } \\
\text { and appropriate control measures of potential equipment failure and operation } \\
\text { errors; Planned control on change of institution, personnel, process, technology, } \\
\text { equipment, operating process and environment that is permanent or temporary } \\
\text { change. } \\
\text { Management and assignment of work including aspects of inappropriate } \\
\text { assignment of team members, insufficient number of team members, lack of team } \\
\text { leader and poor teamwork; Inappropriate operation plan to the actual conditions, } \\
\text { etc. } \\
\text { Those instances when deficiencies among individuals, equipment, training, } \\
\text { or other related safety areas are "known" to the supervisor, yet are allowed to } \\
\text { continue uncorrected. } \\
\text { The willful disregard for existing rules, regulations, instructions, or standard } \\
\text { operating procedures by management during the course of their duties. }\end{array}$ \\
\hline $\begin{array}{l}\text { Level 2: } \\
\text { Preconditions } \\
\text { for unsafe acts }\end{array}$ & $\begin{array}{l}\text { C2: Physical Environment } \\
\text { C3: Conditions of the } \\
\text { operator } \\
\text { C4: Crew resource } \\
\text { management } \\
\text { C5: Personal readiness }\end{array}$ & $\begin{array}{l}\text { Safety warning signs and safety colors complying with the requirements on } \\
\text { equipment or workplace to construction safety; Safety protection measures; Safety } \\
\text { equipment and safety facilities; Safety technical disclosure; The construction } \\
\text { safety technology solutions; Performance and maintenance; Temporary power in } \\
\text { accordance with the provisions to construction safety; The designs of equipment } \\
\text { and controls, display/interface characteristics, checklist layouts, task factors and } \\
\text { automation; Material certificate and material testing; control material production, } \\
\text { transport and stacking. } \\
\text { The operational setting (e.g., weather, altitude, terrain) and the ambient } \\
\text { environment, such as heat, vibration, lighting and toxins. } \\
\text { Pathological conditions such as medical illness, physical trauma, physical fatigue } \\
\text { for individuals. } \\
\text { A variety of communications, coordination, and teamwork issues (including pre- } \\
\text { shift meeting; predicting potential danger activities) that impact performances. } \\
\text { Off-duty activities required to perform optimally on the job such as adhering to } \\
\text { crew rest requirements, alcohol restrictions, and other off-duty mandates; worker's } \\
\text { safety awareness; experience and training result. }\end{array}$ \\
\hline $\begin{array}{l}\text { Level 1: } \\
\text { Unsafe acts }\end{array}$ & $\begin{array}{l}\text { D1: Perception errors } \\
\text { D2: Decision errors } \\
\text { D3: Skill-based errors } \\
\text { D4: Violations }\end{array}$ & $\begin{array}{l}\text { Workers' sense of physical environment and technological environment is } \\
\text { inconsistent with reality (as visual illusion). } \\
\text { misdiagnosed emergency and wrong response to emergency, wrong plan due to } \\
\text { exceeding ability, improper operation and maintenance procedure, poor decision, } \\
\text { and etc. } \\
\text { Wrong operations, omitted step in procedure, poor technique. } \\
\text { Operation and maintenance not in accordance with the standards, not qualified } \\
\text { for mission, fail to properly prepare for work, speeding, and etc. }\end{array}$ \\
\hline
\end{tabular}




$$
\begin{aligned}
& \lambda= \\
& \frac{\sum\left(\max \left(N_{1}, N_{3}\right)+\max \left(N_{2}, N_{4}\right)\right)-\max \left(N_{1}+N_{2}, N_{3}+N_{4}\right)}{N_{1}+N_{2}+N_{3}+N_{4}-\max \left(N_{1}+N_{2}, N_{3}+N_{4}\right)} .
\end{aligned}
$$

At last, we also used odds ratios to estimate the likelihood of the presence of a contributory factor in one HFACS category associated with the concomitant presence of a factor in another category. However, there is a note that odds ratios are an asymmetric measure and they have theoretical meaning when associated with a non-zero value for lambda:

$$
\text { OR }=\frac{N_{1} \cdot N_{4}}{N_{2} \cdot N_{3}}
$$

\section{Data collection and preliminary statistics}

The "Byelaw governing reporting, investigation and handing of production safety accidents" establishes the criteria for the reporting, handling, investigation and the duty of government and accident units. The byelaw stipulates that the reporting of accident should be done on time, accurately, and completely. It also strictly mentions that no unit or individual should be allowed to delay the reporting, miss any content, falsify or hide any fact in the report. Investigation and handling of the accident should be based on the principle of "seeking truth through facts, and respecting science". The goal of such an investigation is to obtain clear answers about the nature of the accident and the manner it happened, identify the losses it resulted in and establish responsibilities for the accident. The goal of the task is to ensure that the units where the accident occurred learn serious lessons from the accident and implement a preventive and corrective action plan to keep such accidents from happening again. The implementation of any such preventive and corrective action plan should be supervised by the trade union and the employees of the affected unit. The causes and subsequent rectification measures are investigated and reported by experts. Therefore, serious accidents which lead to injuries are well documented and information about them is easy to collect. Although the analysis of near misses and accidents with minor injuries is also important indicators of safety management, it is not always reported and investigated. The information of such cases is difficult to collect and hence was not taken into consideration in this study.

Just as "Byelaw governing reporting, investigation and handing of production safety accidents" stipulates, accident investigation group should be formed up by government, production safety supervision department and relevant department responsible for production safety supervision, supervision department, public security department and trade union; the local people procurator shall be invited too. Members of the investigation group should possess knowledge and expertise required by the investigation into the accidents and they should have no interest relationship with the accident under investigation. When the technical authentication is needed in the course of investigation into the accident, the investigation group should entrust the authentication to the unit that has qualifications required by the state. When necessary, the investigation group may directly organize specialists for the technical authentication and appraisal, and the time for technical appraisal and authentication shall not be included in the time limit of the accident investigation. The above rules ensure the accident investigation reports are very authorized and accurate. After the accident investigation finished, the accident relevant unit will get a copy report.

The accident investigation reports were collected from famous Chinese hydropower units, such as the China Three Gorges Corporation, Sino Hydro Corporation, China Energy Engineering Group Co. Ltd. 869 accidents investigation reports were observed between 1979 and 2017 across 194 hydropower construction projects, with a total of 372 injuries and 614 deaths. The collected cases are all personal casualty accidents where at least serious injuries were reported, and both active errors and latent errors are available from the investigation reports.

A complete accident investigation report includes the accident unit, the accident happening process, the active errors and latent errors, the accident nature and the accident handing. After the reports are collected, every case is encoded as "hydropower project name-date" and recorded in a database.

To state the process of reports decomposing, we take the accident investigation report "Baihetan-20120730" as an example. There are mainly three steps of this decomposition. Accident causes (ACs) are identified based on the detailed description of reports in step 1; the identified ACs are assigned into different norms in step 2, and the norms are sub-factors in HFACS framework and they should contain the same category of AC, norms corresponding to any AC will be signed with "1"; match the norms and factors in HFACS framework in step 3, any norm belongs to one factor and the factor will be signed "1" on the condition that the norm has one AC at least. The above work is accomplished by three experts respectively. The step 1 and step 2 of the decomposed report are presented in Table 4.

Table 2. Basic information of experts

\begin{tabular}{|c|l|c|l|l|l|}
\hline ID & Gender & Working seniority & \multicolumn{1}{|c|}{ Profession } & Education & \multicolumn{1}{c|}{ Description } \\
\hline 1 & Male & 10 & Safety managers & Master & Mr Pei came from China Three Gorges Corporation \\
2 & Male & 14 & Construction managers & Bachelor & Mr Gong came from Sino Hydro Corporation \\
3 & Male & 17 & Supervisory engineers & Master & $\begin{array}{l}\text { Mr Song came from Yangtze Three Gorges Technology } \\
\text { \& Economy Development Co., Ltd. }\end{array}$ \\
\hline
\end{tabular}


Table 3. Brief description of HFACS causal categories

\begin{tabular}{|c|l|l|l|}
\hline \multicolumn{2}{|c|}{} & \multicolumn{1}{|c|}{1} & \multicolumn{1}{c|}{ factor A } \\
\hline \multirow{2}{*}{ factor B } & 1 & $N_{1}$ (both of them occur) & $N_{2}$ (factor B occurs but factor A does not) \\
& 0 & $N_{3}$ (factor A occurs but factor B does not) & $N_{4}$ (neither of them occurs) \\
\hline
\end{tabular}

Table 4. The decomposed report

\begin{tabular}{|c|c|}
\hline Accident code & Baihetan-20120730 \\
\hline Project & Baihetan Hydropower Station. \\
\hline consequence & One person death. \\
\hline Accident type & Fall from height. \\
\hline Accident process & $\begin{array}{l}\text { On July 30, 2012, seven people (including worker Tang (dead) and construction monitor Liu) who belonged } \\
\text { to Chongqing Yu Xiang Construction Company went to Baimeng highway bridge pier 1\# of Baihetan } \\
\text { Hydropower construction project to prepare for concrete pouring work, and this task was cancelled later. } \\
\text { Mr Tang fell from height and died on the spot during the process of evacuation. }\end{array}$ \\
\hline Accident rescue & It is irrelevant to the paper topic to be omitted. \\
\hline Accident causes & 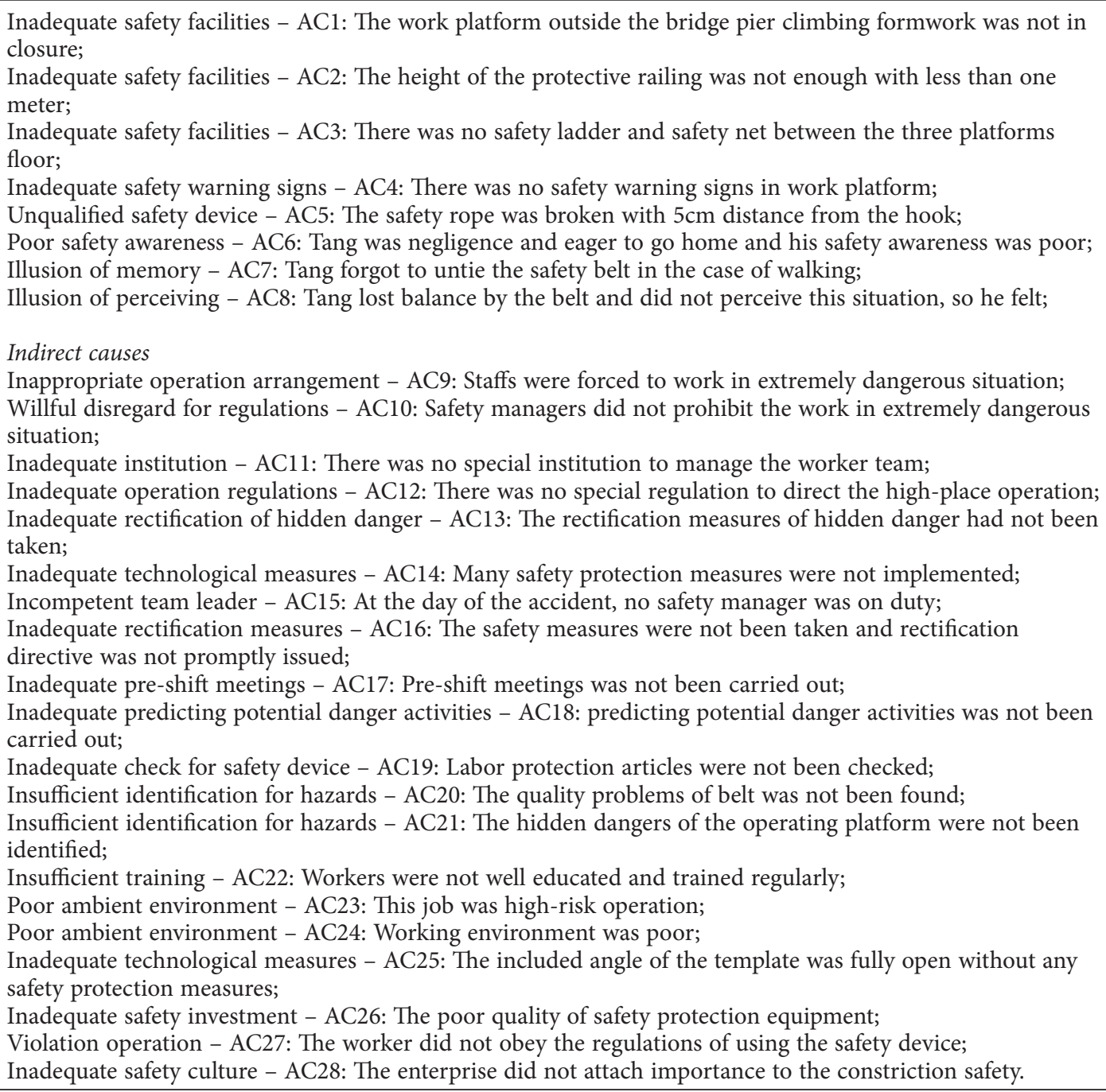 \\
\hline Accident nature & Liability accident. \\
\hline Accident handing & It is irrelevant to the paper topic to be omitted. \\
\hline
\end{tabular}


Table 5. The final decomposing results of the example case "Baihetan-20120730"

\begin{tabular}{|c|c|c|c|c|}
\hline Categories & Accident causes & Norms & factors & mark \\
\hline \multirow{3}{*}{$\begin{array}{l}\text { Level 4: } \\
\text { Organizational } \\
\text { influences }\end{array}$} & AC28 & Poor safety culture & Organizational climate & 1 \\
\hline & $\mathrm{AC} 12$ & Inadequate operation regulations & Operational process & 1 \\
\hline & $\mathrm{AC} 26$ & Inadequate safety investment & Resource management & 1 \\
\hline \multirow{8}{*}{$\begin{array}{l}\text { Level 3: Unsafe } \\
\text { supervisions }\end{array}$} & $\mathrm{AC} 13$ & Inadequate rectification of hidden danger & \multirow[t]{3}{*}{ Inadequate supervision } & \multirow[t]{3}{*}{1} \\
\hline & $\mathrm{AC} 19$ & Inadequate check for safety device & & \\
\hline & AC20/AC21 & Insufficient identification for hazards & & \\
\hline & AC9 & Unreasonable operation arrangement & \multirow[t]{2}{*}{ Planned inappropriate operations } & \multirow[t]{2}{*}{1} \\
\hline & $\mathrm{AC} 11$ & Inadequate institution & & \\
\hline & $\mathrm{AC} 16$ & Inadequate rectification measures & Failed to correct known problems & 1 \\
\hline & $\mathrm{AC} 10$ & Willful disregard for regulations & \multirow[t]{2}{*}{ Supervisory violations } & 1 \\
\hline & $\mathrm{AC} 15$ & Authorize unqualified staff for duty & & \\
\hline \multirow{10}{*}{$\begin{array}{l}\text { Level 2: Pre- } \\
\text { conditions for } \\
\text { unsafe acts }\end{array}$} & $\mathrm{AC} 1 / \mathrm{AC} 2 / \mathrm{AC} 3$ & Inadequate safety facilities & \multirow[t]{4}{*}{ Technological environment } & \multirow[t]{4}{*}{1} \\
\hline & $\mathrm{AC} 4$ & Inadequate safety warning signs & & \\
\hline & AC5 & Unqualified safety device & & \\
\hline & $\mathrm{AC} 14 / \mathrm{AC} 25$ & Inadequate safety protection measures & & \\
\hline & $\mathrm{AC} 23 / \mathrm{AC} 24$ & Poor ambient environment & Physical environment & 1 \\
\hline & None & None & Conditions of the operator & 0 \\
\hline & $\mathrm{AC} 17$ & Inadequate pre-shift meetings & \multirow[t]{2}{*}{ Crew resource management } & \multirow[t]{2}{*}{1} \\
\hline & $\mathrm{AC} 18$ & $\begin{array}{l}\text { Inadequate predicting potential danger activi- } \\
\text { ties }\end{array}$ & & \\
\hline & $\mathrm{AC} 22$ & Insufficient training & \multirow[t]{2}{*}{ Personal readiness } & \multirow[t]{2}{*}{1} \\
\hline & AC6 & Poor safety awareness & & \\
\hline \multirow{5}{*}{$\begin{array}{l}\text { Level 1: Unsafe } \\
\text { acts }\end{array}$} & $\mathrm{AC7}$ & Illusion of memory & \multirow[t]{2}{*}{ Perception errors } & \multirow[t]{2}{*}{1} \\
\hline & AC8 & Illusion of perceiving & & \\
\hline & None & None & Decision errors & 0 \\
\hline & None & None & Skill-based errors & 0 \\
\hline & $\mathrm{AC} 27$ & $\begin{array}{l}\text { Operation not in accordance with the regula- } \\
\text { tions }\end{array}$ & Violations & 1 \\
\hline
\end{tabular}

A factor will be marked as " 1 " if it consists of any norm and marked as " 0 " vice versa. The final decomposing results of the example case "Baihetan-20120730" are presented in Table 5. We conduct the same process for all collected reports and all accidents are decomposed by the above steps.

The raters conduct the same analysis and decomposition for all the collected reports, and they have their own results, the three experts discuss together to reach the same results when there are some conflicts.

According to the "The classification for casualty accidents of enterprise staff and workers" (NO: 658.382 GB6441-86), 869 cases can be divided into 20 types based on the accident results. The type and the number of occurrences of each accident type are reported in Table 6.

From Table 6, we can see that the three largest types of accidents are a) fall from height, b) traffic accident and c) hit by objects. The next large proportions of accident types are crane injury, collapse accident, machine injury and electric shock. A small proportion of accidents, which does not fall into any of the above types, have been grouped together into other types of accidents.

To facilitate the classification of accidents in the category of "fall from height", a high-altitude operation is defined as an operation where a person works at a height of 2 meters or more and has the possibility of falling. The accident is defined as "fall from height" if the person falls during such an operation. There were 224 reported cases of fall from height accidents among the collected samples, accounting for $25.78 \%$ of the total number of accidents.

A traffic accident is defined as a personal injury or loss of property by a vehicle due to the fault of the driver or another party or due to unforeseen circumstances. This definition is provided by the provisions in the 119th article of the "Law of the people's Republic of China on road traffic safety" (Order of the Chairman of the People's Republic of China (No: 47)). However, driving operation in the context of hydropower construction has the following characteristics: (1) the road is in the internal construction site instead of being an outbound traffic road; (2) the vehicles 
are special vehicles used in the construction site; (3) most drivers are peasant-workers. There were 176 reported traffic accidents, accounting for $20.25 \%$ of the total of 869 accidents investigated in this paper.

The next category of accidents which are termed as hit by objects is defined as an accident in which a person is injured by the inertial force of an uncontrolled object. This definition is adopted from the "The classification for casualty accidents of enterprise staff and workers" (NO: 658.382 GB6441-86). In our collected accident statistics, there are 130 hit by objects accidents that account for $12.41 \%$ of all the accidents studied.

The distribution of the other categories of accidents is as follows: $6.9 \%$ of collected accidents are crane injuries; the proportions of collapse accidents, machine injury accidents and electric shocks are 8.29\%, 5.75\% and 5.06\%, respectively. The category "other accidents", which accounts for only $13.01 \%$ of the total number includes all accidents which do not fall into one of the seven categories above.

Table 6. The statistics of different accident types

\begin{tabular}{|c|c|c|c|}
\hline $\begin{array}{l}\text { Accidents } \\
\text { types }\end{array}$ & $\begin{array}{l}\text { Number of } \\
\text { occurrences }\end{array}$ & Accidents types & $\begin{array}{l}\text { Number of } \\
\text { occurrences }\end{array}$ \\
\hline $\begin{array}{l}\text { Fall from } \\
\text { height }\end{array}$ & 224 & $\begin{array}{l}\text { Drowning } \\
\text { accident }\end{array}$ & 10 \\
\hline $\begin{array}{l}\text { Traffic } \\
\text { accident }\end{array}$ & 176 & Scald accident & 7 \\
\hline Hit by objects & 130 & $\begin{array}{l}\text { Permeable } \\
\text { accident }\end{array}$ & 11 \\
\hline Crane injury & 60 & Gas accident & 7 \\
\hline $\begin{array}{l}\text { Collapse } \\
\text { accident }\end{array}$ & 72 & Boiler explosion & 7 \\
\hline $\begin{array}{l}\text { Machine } \\
\text { injury }\end{array}$ & 50 & $\begin{array}{l}\text { Vessel explosion } \\
\text { accident }\end{array}$ & 5 \\
\hline Electric shock & 44 & $\begin{array}{l}\text { Other type of } \\
\text { explosion }\end{array}$ & 3 \\
\hline $\begin{array}{l}\text { Roof fall } \\
\text { accident }\end{array}$ & 20 & $\begin{array}{l}\text { Gunpowder } \\
\text { explosion }\end{array}$ & 11 \\
\hline $\begin{array}{l}\text { Shooting } \\
\text { accident }\end{array}$ & 15 & Poisoning choke & 3 \\
\hline Fire disaster & 12 & Other accident & 2 \\
\hline
\end{tabular}

\section{Results}

\subsection{Factors and norms ranking}

Before the rater discussion together, the inter-rater reliability, measured on a category-by-category basis, should be calculated by Cohen's Kappa to assess their consistency. The half categories that the Kappa values exceed 0.4 are regarded acceptable. The inter-rater reliability between raters is also given in Table 7 , in which the data comes from the analyses in the first round. The results show that inter-rater consistency varies between raters from 52\%$94 \%$ and are well above the 50\% threshold, indicating acceptable reliability between rater 1 and rater 2 , rater 1 and rater 3 , rater 2 and rater 3 .
Table 7. Inter-rater reliability statistics

\begin{tabular}{|cccc|}
\hline Factors & $\begin{array}{c}\text { Rater 1 vs } \\
\text { Rater 2 }\end{array}$ & $\begin{array}{c}\text { Rater 1 vs } \\
\text { Rater 3 }\end{array}$ & $\begin{array}{c}\text { Rater 2 vs } \\
\text { Rater 3 }\end{array}$ \\
\hline A1 & 0.64 & 0.76 & 0.65 \\
\hline A2 & 0.67 & 0.7 & 0.76 \\
\hline A3 & 0.55 & 0.78 & 0.56 \\
\hline B1 & 0.74 & 0.62 & 0.87 \\
\hline B2 & 0.83 & 0.75 & 0.71 \\
\hline B3 & 0.91 & 0.68 & 0.67 \\
\hline B4 & 0.56 & 0.62 & 0.71 \\
\hline C1 & 0.87 & 0.68 & 0.84 \\
\hline C2 & 0.69 & 0.81 & 0.86 \\
\hline C3 & 0.92 & 0.55 & 0.86 \\
\hline C4 & 0.76 & 0.83 & 0.75 \\
\hline C5 & 0.77 & 0.78 & 0.65 \\
\hline D1 & 0.75 & 0.71 & 0.67 \\
\hline D2 & 0.72 & 0.59 & 0.87 \\
\hline D3 & 0.73 & 0.74 & 0.9 \\
\hline D4 & 0.78 & 0.82 & 0.69 \\
\hline $\begin{array}{l}\text { Note that the percentages in the table will not equal } 100 \%, \\
\text { because in many reports more than one causal factor was } \\
\text { associated with the accident/incident. }\end{array}$ \\
\hline
\end{tabular}

\subsection{Inter-rater reliability results}

According to the decomposing steps and the framework of HFACS, the human error database is built. From the statistics results, the three highest frequency accident types are identified: the first type is fall from height, the second type is traffic accident and the third type is hit by objects. Our study mainly concerns on these three types. The factors frequency of them could be calculated and the results are presented in the Table 8 .

It can be found that the different accident types have different factors rankings, and the consistency of these rankings is very low. The first four human factors with the largest percentage of occurrence in all the three accident types are highlighted in bold in Table 8. For fall from height accidents, the first four are C5 "personal readiness", B1 “inadequate supervision", D4 "violations" and B4 "supervisory violations". For traffic accidents, the first four human errors are same with that of fall from height with a different factor ranking, and they ranked with the order of B1, C5, D4 and B4. For hit by objects, it has some own characteristics. Compared with the two other accident types, most hit by objects accidents are firstly caused by objects thrown from height and secondly caused by rolling rocks from steep hillsides where hidden dangers are not identified. Thus the four human errors are B1 "inadequate supervision", C5 "personal readiness", B4 "supervisory violations" and C1 "technological environment" that replaces D4 "violations". 
The norms of five factors which have highest frequency are obtained by the process of decomposing steps. One factor may have a large number of norms and some of them play a less important role with low frequency. Therefore, the important norms which have higher frequency will be paid more attention to and presented in Tables 9a-9e.

Table 8. The factors frequency of different accident types

\begin{tabular}{|c|c|c|c|c|c|c|c|c|c|}
\hline \multirow{2}{*}{ Factors } & \multicolumn{3}{|c|}{ Fall from accident } & \multicolumn{3}{c|}{ Traffic accident } & \multicolumn{3}{c|}{ Hit by objects } \\
\cline { 2 - 11 } & Frequency & Percentage & Rank & Frequency & Percentage & Rank & Frequency & Percentage & Rank \\
\hline A1 & 111 & 0.496 & 9 & 91 & 0.517 & 8 & 84 & 0.646 & 5 \\
\hline A2 & 98 & 0.438 & 11 & 82 & 0.466 & 9 & 56 & 0.431 & 10 \\
\hline A3 & 88 & 0.393 & 13 & 24 & 0.136 & 14 & 31 & 0.238 & 12 \\
\hline B1 & 188 & 0.839 & 2 & 142 & 0.807 & 1 & 115 & 0.885 & 1 \\
\hline B2 & 119 & 0.531 & 7 & 59 & 0.335 & 13 & 67 & 0.515 & 8 \\
\hline B3 & 50 & 0.223 & 14 & 15 & 0.085 & 16 & 17 & 0.131 & 13 \\
\hline B4 & 150 & 0.670 & 4 & 130 & 0.739 & 4 & 99 & 0.762 & 3 \\
\hline C1 & 134 & 0.598 & 5 & 96 & 0.545 & 7 & 89 & 0.685 & 4 \\
\hline C2 & 121 & 0.540 & 6 & 80 & 0.455 & 10 & 78 & 0.600 & 6 \\
\hline C3 & 101 & 0.451 & 10 & 21 & 0.119 & 15 & 5 & 0.038 & 16 \\
\hline C4 & 98 & 0.438 & 12 & 112 & 0.636 & 6 & 76 & 0.585 & 7 \\
\hline C5 & 204 & 0.911 & 1 & 140 & 0.795 & 2 & 109 & 0.838 & 2 \\
\hline D1 & 112 & 0.500 & 8 & 122 & 0.693 & 5 & 65 & 0.500 & 9 \\
\hline D2 & 10 & 0.045 & 16 & 71 & 0.403 & 11 & 10 & 0.077 & 14 \\
\hline D3 & 19 & 0.085 & 15 & 62 & 0.352 & 12 & 9 & 0.069 & 15 \\
\hline D4 & 176 & 0.786 & 3 & 135 & 0.767 & 3 & 41 & 0.315 & 16 \\
\hline
\end{tabular}

Table 9a. The norms of factor "personal readiness" (main norms)

\begin{tabular}{|l|c|c|c|c|c|c|c|c|c|}
\hline \multirow{2}{*}{ Norms } & \multicolumn{3}{|c|}{ Fall from height } & \multicolumn{3}{c|}{ Traffic accident } & \multicolumn{3}{c|}{ Hit by objects } \\
\cline { 2 - 11 } & Frequency & Percentage & Rank & Frequency & Percentage & Rank & Frequency & Percentage & Rank \\
\hline $\begin{array}{l}\text { Poor safety } \\
\text { awareness }\end{array}$ & 188 & 0.922 & 1 & 132 & 0.943 & 1 & 103 & 0.945 & 1 \\
\hline Poor training results & 99 & 0.485 & 4 & 124 & 0.886 & 2 & 85 & 0.780 & 2 \\
\hline Insufficient sleeping & 35 & 0.172 & 6 & 15 & 0.107 & 7 & 7 & 0.064 & 7 \\
\hline Drinking too much & 7 & 0.034 & 7 & 16 & 0.114 & 6 & 8 & 0.073 & 6 \\
\hline $\begin{array}{l}\text { Unfamiliar with } \\
\text { construction site }\end{array}$ & 132 & 0.647 & 2 & 94 & 0.671 & 3 & 9 & 0.083 & 5 \\
\hline $\begin{array}{l}\text { Unfamiliar with the } \\
\text { operation type }\end{array}$ & 65 & 0.319 & 5 & 65 & 0.464 & 4 & 12 & 0.110 & 4 \\
\hline $\begin{array}{l}\text { Unfamiliar with } \\
\text { operation procedure }\end{array}$ & 122 & 0.598 & 3 & 55 & 0.393 & 5 & 19 & 0.174 & 3 \\
\hline
\end{tabular}

Table 9b. The norms of factor "supervisory violations" (main norms)

\begin{tabular}{|l|c|c|c|c|c|c|c|c|c|}
\hline \multirow{2}{*}{ Norms } & \multicolumn{3}{c|}{ Fall from height } & \multicolumn{3}{c|}{ Traffic accident } & \multicolumn{3}{c|}{ Hit by objects } \\
\cline { 2 - 11 } & Frequency & Percentage & Rank & Frequency & Percentage & Rank & Frequency & Percentage & Rank \\
\hline $\begin{array}{l}\text { Authorize } \\
\text { unqualified staff for } \\
\text { duty }\end{array}$ & 154 & 0.755 & 2 & 99 & 0.707 & 3 & 102 & 0.936 & 2 \\
\hline $\begin{array}{l}\text { Authorize mission } \\
\text { with deregulation }\end{array}$ & 136 & 0.667 & 3 & 131 & 0.871 & 2 & 70 & 0.642 & 3 \\
\hline $\begin{array}{l}\text { Fail to enforce rules } \\
\text { and regulations }\end{array}$ & 194 & 0.951 & 1 & 122 & 0.936 & 1 & 104 & 0.954 & 1 \\
\hline
\end{tabular}


Table 9c. The norms of factor "inadequate supervision" (main norms)

\begin{tabular}{|l|c|c|c|c|c|c|c|c|c|}
\hline \multicolumn{1}{|c|}{ Norms } & \multicolumn{3}{c|}{ Fall from height } & \multicolumn{3}{c|}{ Traffic accident } & \multicolumn{3}{c|}{ Hit by objects } \\
\cline { 2 - 10 } & Frequency & Percentage & Rank & Frequency & Percentage & Rank & Frequency & Percentage & Rank \\
\hline $\begin{array}{l}\text { Insufficient } \\
\text { identification for } \\
\text { hazards }\end{array}$ & 56 & 0.275 & 6 & 86 & 0.614 & 6 & 89 & 0.817 & 2 \\
\hline $\begin{array}{l}\text { Poor supervision of } \\
\text { construction sites }\end{array}$ & 129 & 0.632 & 5 & 92 & 0.657 & 5 & 86 & 0.789 & 3 \\
\hline $\begin{array}{l}\text { Poor oversight of } \\
\text { environment }\end{array}$ & 184 & 0.902 & 2 & 101 & 0.721 & 3 & 5 & 0.046 & 7 \\
\hline $\begin{array}{l}\text { Poor oversight of } \\
\text { personnel }\end{array}$ & 143 & 0.701 & 4 & 97 & 0.693 & 4 & 66 & 0.606 & 4 \\
\hline $\begin{array}{l}\text { Inadequate control } \\
\text { of error operation }\end{array}$ & 155 & 0.760 & 3 & 29 & 0.207 & 7 & 32 & 0.294 & 5 \\
\hline $\begin{array}{l}\text { Inadequate control } \\
\text { of potential failure }\end{array}$ & 21 & 0.103 & 7 & 111 & 0.793 & 2 & 21 & 0.193 & 6 \\
\hline $\begin{array}{l}\text { Insufficient educa- } \\
\text { tion and training }\end{array}$ & 192 & 0.941 & 1 & 124 & 0.886 & 1 & 101 & 0.927 & 1 \\
\hline
\end{tabular}

Table 9d. The norms of factor "violations" (main norms)

\begin{tabular}{|l|c|c|c|c|c|c|}
\hline \multirow{2}{*}{ Norms } & \multicolumn{3}{c|}{ Fall from height } & \multicolumn{4}{c|}{ Traffic accident } \\
\cline { 2 - 7 } & Frequency & Percentage & Rank & Frequency & Percentage & Rank \\
\hline Operation not in accordance with the procedures & 91 & 0.446 & 4 & 87 & 0.621 & 4 \\
\hline Operation not in accordance with the regulations & 179 & 0.877 & 1 & 122 & 0.871 & 1 \\
\hline Not qualified for mission & 49 & 0.240 & 5 & 95 & 0.679 & 2 \\
\hline No properly prepare for work & 98 & 0.480 & 3 & 79 & 0.564 & 5 \\
\hline Speeding & 9 & 0.044 & 6 & 89 & 0.636 & 3 \\
\hline Use seat belts wrongly & 111 & 0.544 & 2 & 7 & 0.050 & 6 \\
\hline
\end{tabular}

Table 9e. The norms of factor "technological environment" (main norms)

\begin{tabular}{|l|c|c|c|}
\hline \multirow{2}{*}{ Norms } & \multicolumn{3}{c|}{ Hit by objects } \\
\cline { 2 - 4 } & Frequency & Percentage & Rank \\
\hline No safety warning signs & 67 & 0.615 & 2 \\
\hline No safety colors & 43 & 0.394 & 3 \\
\hline $\begin{array}{l}\text { Inadequate safety } \\
\text { protection measures }\end{array}$ & 85 & 0.780 & 1 \\
\hline $\begin{array}{l}\text { Poor safety } \\
\text { technological solutions }\end{array}$ & 7 & 0.064 & 4 \\
\hline
\end{tabular}

\subsection{Correlation analysis}

The important factors of the three accident types have been determined using factors ranking. The ranking can only tell us which factor we should pay more attention to, but it could not reveal the inner relationship of factors between different levels. The correlation analysis can achieve this goal with Chi-square, lambda and odd ratio parameters.

Each relationship has three parameters and is calculated by Eqns (1)-(3), i.e., Chi-square, lambda and odd ra- tio. The two different factors have association if the value of chi-square is in excess of 3.84 and the value of lambda is zero; the significant association indicates that the value of chi-square is in excess of 3.84 and the value of lambda is in the interval of $(0,0.5]$; the extremely significant association indicates that the value of chi-square is in excess of 3.84 and the value of lambda is in the interval of $(0.5,1]$.

For fall from height accident type, there are 20 relationships showed associations: two of them meet the chisquare condition but lambda zero, twelve of them meet the chi-square condition and lambda between zero and 50\%, six relationships have lambda which is in excess of $50 \%$. For traffic accident type, there are 16 relationships showed associations: three of them meet the chi-square condition but lambda zero, nine of them meet the chi-square condition and lambda between zero and $50 \%$, four relationships have lambda which is in excess of $50 \%$. For hit by objects accident type, there are 15 relationships showed associations: four of them meet the chi-square condition but lambda zero, eight relationships meet the chi-square condition and lambda between zero and 50\%, three relationships have lambda which is in excess of $50 \%$. The results are presented in Table 10, and the simple associations graphs are presented in Figures 2 to 4. 
Table 10. The results of relevancy analysis

\begin{tabular}{|c|c|c|c|c|c|c|c|c|c|}
\hline \multirow{2}{*}{$\begin{array}{l}\text { The significant correlation between factors } \\
\text { in the HFACS framework }\end{array}$} & \multicolumn{3}{|c|}{ Fall from height } & \multicolumn{3}{|c|}{ Traffic accident } & \multicolumn{3}{|c|}{ Hit by objects } \\
\hline & $\begin{array}{c}\text { Chi- } \\
\text { square }\end{array}$ & Lambda & $\begin{array}{l}\text { Odd } \\
\text { ratio }\end{array}$ & $\begin{array}{c}\text { Chi- } \\
\text { square }\end{array}$ & Lambda & $\begin{array}{l}\text { Odd } \\
\text { ratio }\end{array}$ & $\begin{array}{c}\text { Chi- } \\
\text { square }\end{array}$ & Lambda & $\begin{array}{l}\text { Odd } \\
\text { ratio }\end{array}$ \\
\hline \multicolumn{10}{|l|}{$\begin{array}{l}\text { HFACS level-4 association with level-3 } \\
\text { categories }\end{array}$} \\
\hline $\begin{array}{l}\text { Organizational climate to inadequate } \\
\text { supervision }\end{array}$ & & & & & & & 8.133 & 0 & 0 \\
\hline $\begin{array}{l}\text { Organizational climate to planned inappro- } \\
\text { priate operations }\end{array}$ & 11.623 & 0.512 & 11.231 & 17.226 & 0.514 & 34.421 & 21.313 & 0.711 & 9.219 \\
\hline $\begin{array}{l}\text { Organizational climate to supervisory } \\
\text { violations }\end{array}$ & 24.142 & 0.537 & 0.089 & & & & & & \\
\hline Operational process to inadequate supervision & 42.445 & 0.234 & 3.620 & 22.189 & 0.667 & 7.891 & 14.921 & 0.351 & 0.010 \\
\hline $\begin{array}{l}\text { Operational process to planned inappropri- } \\
\text { ate operations }\end{array}$ & 25.013 & 0.109 & 0.037 & & & & & & \\
\hline $\begin{array}{l}\text { Resource management to failed to correct } \\
\text { known problems }\end{array}$ & 56.770 & 0.707 & 31.43 & 3.990 & 0.109 & 6.108 & & & \\
\hline \multicolumn{10}{|l|}{$\begin{array}{l}\text { HFACS level-3 association with level-2 } \\
\text { categories }\end{array}$} \\
\hline $\begin{array}{l}\text { Inadequate supervision to technological } \\
\text { environment }\end{array}$ & 12.23 & 0.240 & 21.400 & 7.343 & 0.424 & 7.000 & 15.329 & 0.901 & 4.734 \\
\hline $\begin{array}{l}\text { Inadequate supervision to physical } \\
\text { environment }\end{array}$ & 7.130 & 0 & 0 & & & & & & \\
\hline $\begin{array}{l}\text { Inadequate supervision to condition of the } \\
\text { operator }\end{array}$ & 8.912 & 0.124 & 2.891 & 21.232 & 0 & 0 & 17.321 & 0 & 0 \\
\hline Inadequate supervision to personal readiness & 33.106 & 0.657 & 12.32 & 12.210 & 0.218 & 17.51 & 13.727 & 0.422 & 16.551 \\
\hline $\begin{array}{l}\text { Planned inappropriate operations to crew } \\
\text { resource management }\end{array}$ & 32.466 & 0.379 & 9.324 & 10.981 & 0.190 & 6.127 & 7.319 & 0.351 & 21.324 \\
\hline $\begin{array}{l}\text { Failed to correct known problems to } \\
\text { technological environment }\end{array}$ & 13.234 & 0.453 & 1.842 & & & & & & \\
\hline $\begin{array}{l}\text { Supervisory violations to technological } \\
\text { environment }\end{array}$ & 34.045 & 0.421 & 21.210 & & & & & & \\
\hline $\begin{array}{l}\text { Supervisory violations to condition of the } \\
\text { operator }\end{array}$ & & & & 6.554 & 0 & 0 & & & \\
\hline $\begin{array}{l}\text { Supervisory violations to crew resource } \\
\text { management }\end{array}$ & 16.464 & 0.201 & 17.921 & 9.290 & 0.451 & 15.261 & 4.420 & 0.234 & 8.241 \\
\hline Supervisory violations to personal readiness & 44.304 & 0.511 & 7.131 & 27.273 & 0.853 & 8.921 & 8.764 & 0.721 & 12.110 \\
\hline \multicolumn{10}{|l|}{$\begin{array}{l}\text { HFACS level-2 association with level-1 } \\
\text { categories }\end{array}$} \\
\hline Technological environment to perception errors & 10.710 & 0.231 & 4.334 & & & & 9.234 & 0.791 & 2.900 \\
\hline Physical environment to perception errors & & & & 7.897 & 0.419 & 1.278 & & & \\
\hline Physical environment to violations & 14.121 & 0 & 0 & & & & & & \\
\hline Condition of the operator to decision errors & & & & & & & 8.724 & 0 & 0 \\
\hline Condition of the operator to skill-based errors & & & & & & & 13.246 & 0 & 0 \\
\hline Crew resource management to perception errors & 20.114 & 0.411 & 6.032 & & & & & & \\
\hline Crew resource management to violations & & & & 5.678 & 0 & 0 & & & \\
\hline Personal readiness to perception errors & 34.108 & 0.723 & 13.32 & 9.357 & 0.378 & 7.340 & 8.021 & 0.182 & 2.832 \\
\hline Personal readiness to decision errors & 77.881 & 0.822 & 12.57 & 12.476 & 0.417 & 1.680 & 13.274 & 0.280 & 0.010 \\
\hline Personal readiness to skill-based errors & 54.818 & 0.912 & 1.560 & 15.309 & 0.509 & 10.430 & 8.218 & 0.310 & 0.030 \\
\hline Personal readiness to violations & 75.371 & 0.731 & 4.175 & 16.589 & 0.591 & 15.657 & 10.178 & 0.23 & 4.669 \\
\hline
\end{tabular}




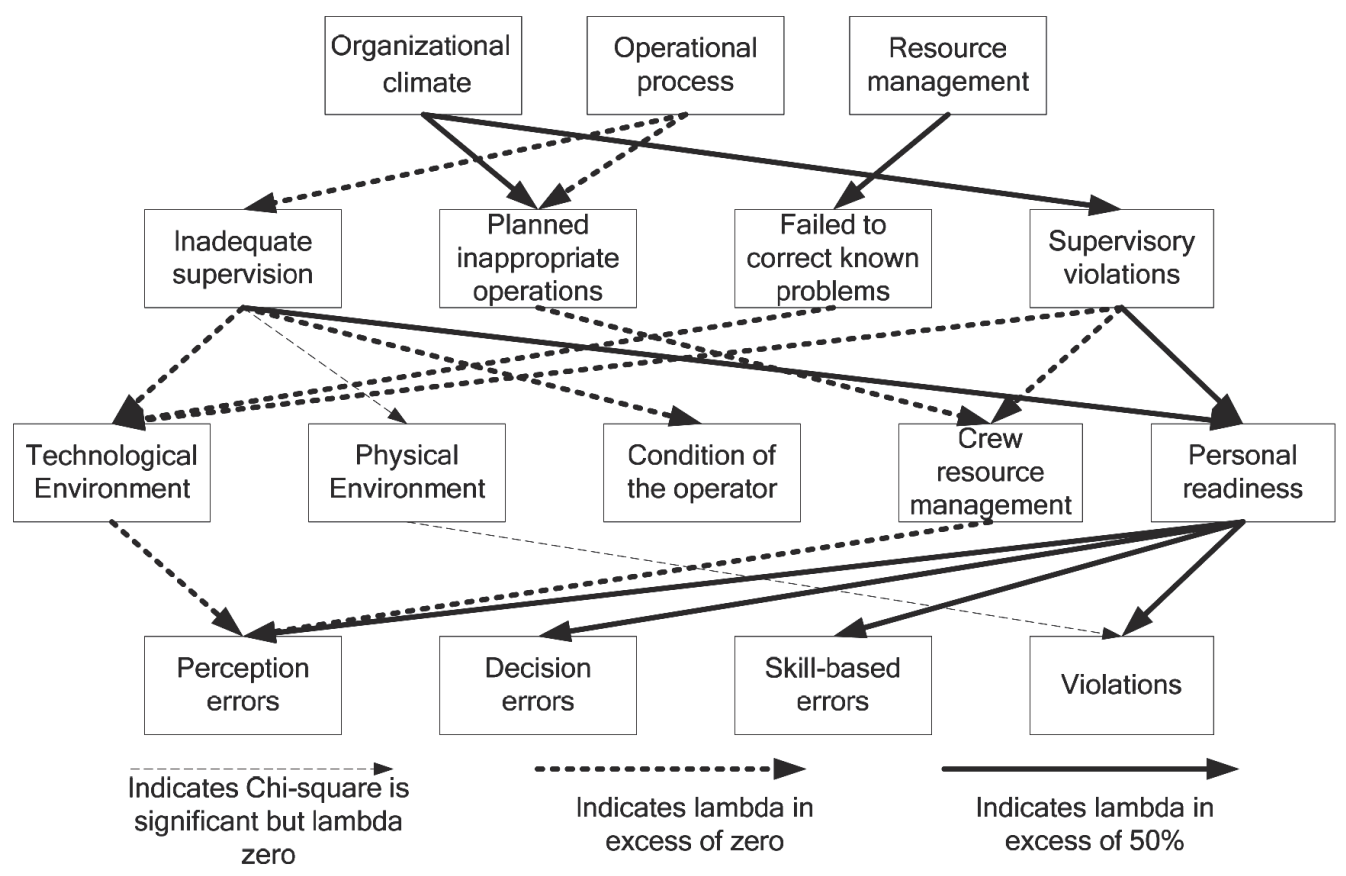

Figure 2. The simple associations graphs of fall from height accident type

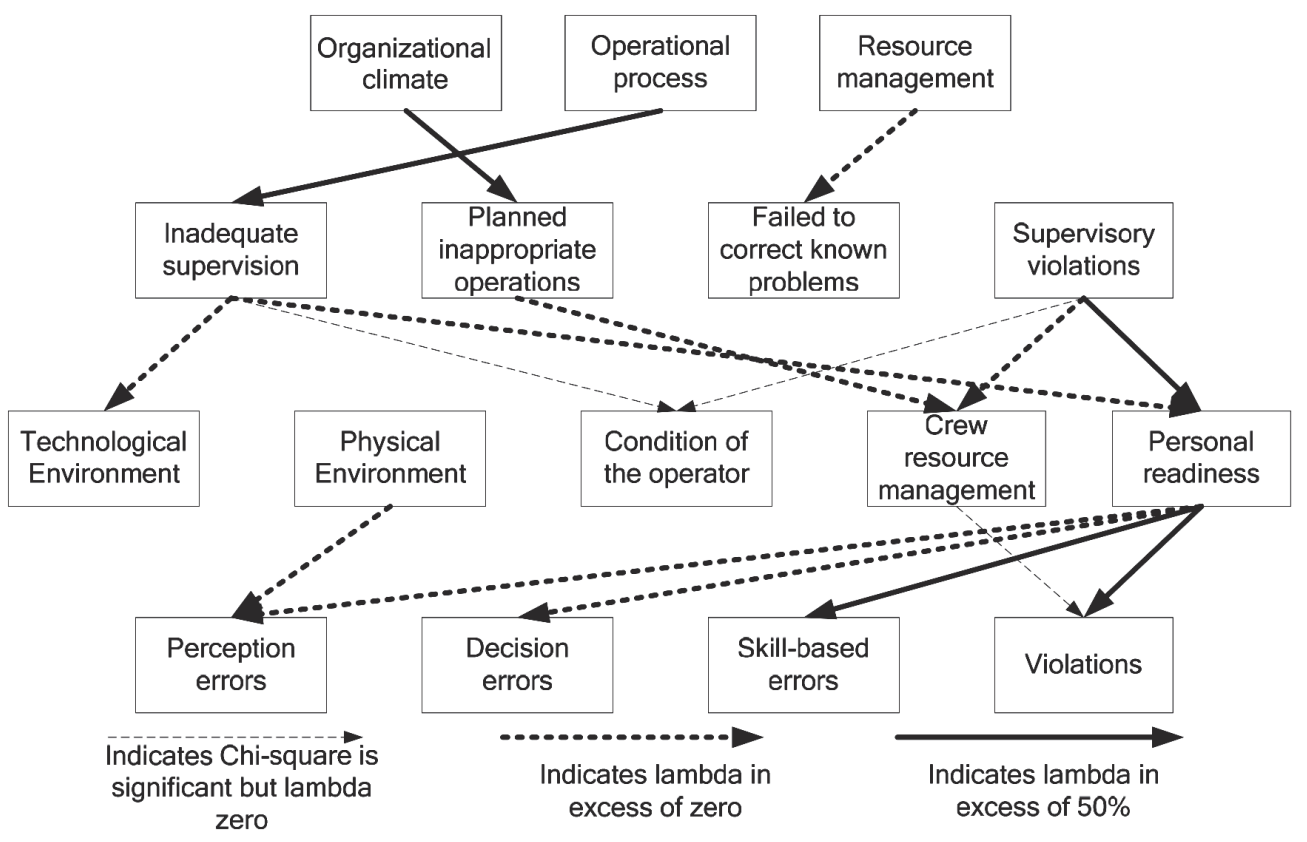

Figure 3. The simple associations graphs of traffic accident type

\section{Discussion}

\subsection{Routes to failure}

From Figures 2 to 4 , the routes to failure are revealed from the organizational aspects of construction safety and safety management systems to the workers' behaviors, which are obviously different for unique characteristics of each accidents type. There are more failure routes in fall from height accident type, which means many routes can lead the accident and the accident forming process is more complex. In fall from height accident type, the main fail- ure route is "A $2 \rightarrow \mathrm{B} 1 \rightarrow \mathrm{C} 5 \rightarrow \mathrm{D}(1,2,3,4)$ or $\mathrm{A} 1 \rightarrow \mathrm{B} 4 \rightarrow \mathrm{C} 5 \rightarrow \mathrm{D}$ $(1,2,3,4)$ " the factor "personal readiness" is in the key place. In the traffic accident type, the main failure route is " $\mathrm{A} 2 \rightarrow \mathrm{B} 1 \rightarrow \mathrm{C} 5 \rightarrow \mathrm{D}(3,4)$ or $\mathrm{A} 1 \rightarrow \mathrm{B} 2 \rightarrow \mathrm{C} 5 \rightarrow \mathrm{D}(3,4)$ ", which has some similarities with the first type. In hit by objects accident type, $A 2 \rightarrow B 1 \rightarrow C 5 \rightarrow D(1,2,3,4)$ also is the main route. Generally speaking, the failure routes between different accident types are similar in macroscopic view. But in the microcosmic view, they have many obvious differences. 


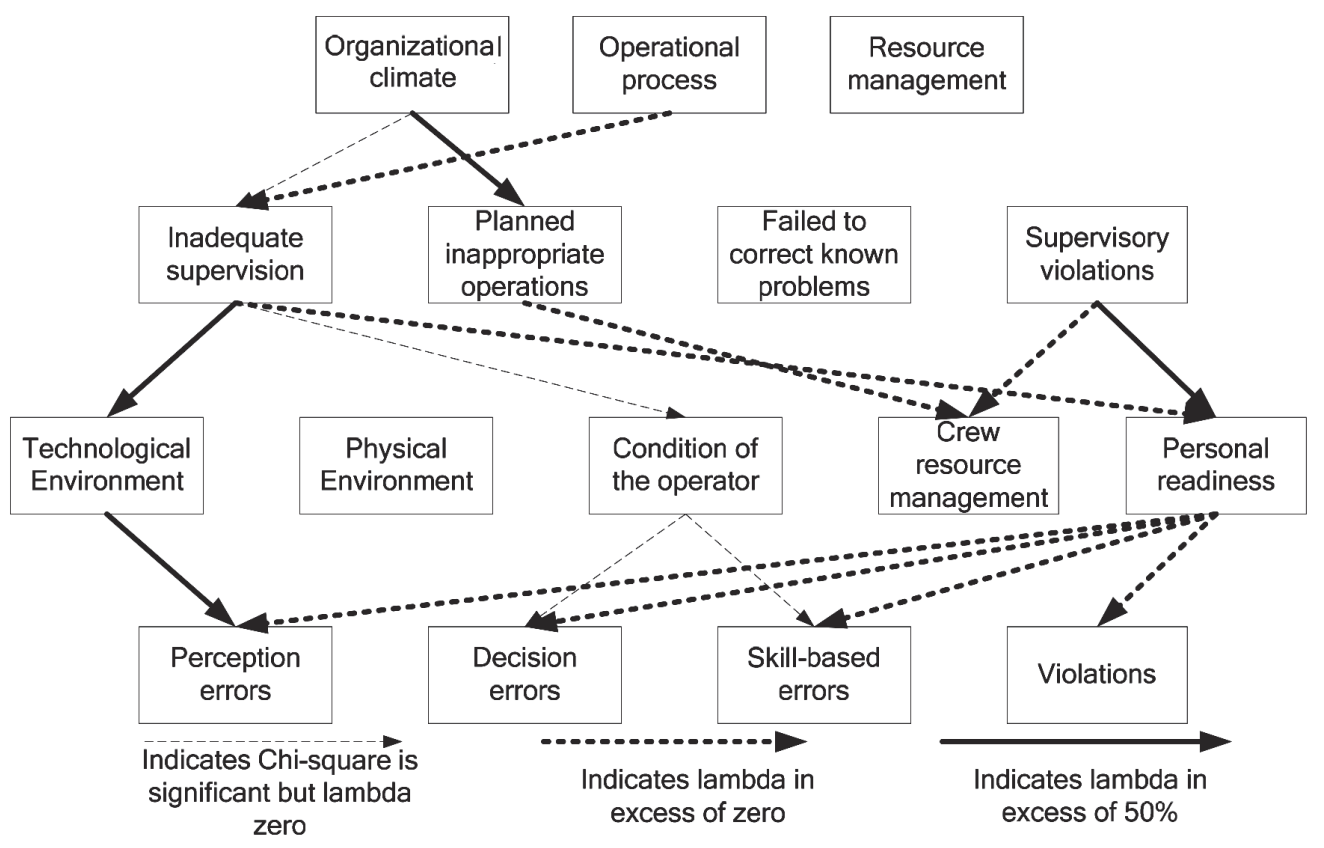

Figure 4. The simple associations graphs of hit by objects accident type

In the association analysis between level four "organizational influences" and level three "unsafe supervisions", there is no relationship that the chi-square excesses 3.84 while lambda is zero in fall from height and traffic accidents; but in hit by objects accident, the factors "organizational climate" and "inadequate supervision" have slight association because the chi-square excesses 3.84 but lambda zero. In all three accident types, the "organizational climate" has a significant association with "planned inappropriate operations". The unsubstantial organizational climate will lead to the weak safety atmosphere, and the leader pursues the rate of progress and cost neglecting the safety and quality (Clarke, Ward 2006). Concretely, inappropriate assignment of team members, and insufficient number of team members, and lack of team leader and poor teamwork; and inappropriate operation plan to the actual conditions, etc. are the main content of factor "planned inappropriate operations". There is a special relationship between the factor "organizational climate" and "supervisory violations" in fall from height. There is much cooperative work of multi-team in hydropower construction with lager number of cross operations, and many work teams are dispersed in the same vertical direction. A typical supervisory violation is that the team manager only concerns the safety of his/her own team operators. The safety awareness and responsibility of managers are poor with weak organizational climate (Cooper, Phillips 2004), which results in a fluke mind and deregulation of throwing objects or sundries arrangement in mess.

In three accident types, there is a same relationship between "operational process" and "inadequate supervision" and traffic accident have a stronger association of this relationship. In the hydropower construction, procedures for warning and risk avoidance should be established in the prior of safety management based on the prefect management system and means, the right management goals and ideas, the detailed and operational laws and regulations to improve the level of supervision. Besides, there is a significant association between "operational process" and "planned inappropriate operations" in fall from height. Operation process including operations, procedures, etc. determines the work conditions and reasonable level and formation of team member. Just as the example presented in the section 3 , that staffs were forced to work in extremely dangerous situation is an element of factor "planned inappropriate operations", but the essential reason is unclear clarification of responsibility from the procedures in "operational process".

In the fall from height and traffic accident, "resource management" has a significant effect on the factor "failed to correct known problems", and the association in fall from height accident type is stronger than that in traffic accident type. In the hydropower construction, the operators should be equipped with qualified protection device and the construction site should be set good technological measures. The manager has a fluke mind that the inadequate device or measures have low accident possibility, and the resource is not used to correct the imperfection timely when the problems of these device and measures are found. However, in the traffic accident type, the factor "failed to correct known problems" mainly indicates that the known malfunctions of vehicle can't be repaired timely for shortage of money, thus the relationship of the two factors is more single relatively.

In fall from height, the relationships between the third and second levels are more complex than those in the two other accident types. There are three factors of "inadequate supervision", "failed to correct known problems" and “ 
supervisory violations", in the upper level that has significant associations with "technological environment". The good technical environment is a guarantee for the safety operation in the hydropower construction. Working at heights is a type of special operation which requires high level skills and psychological quality. Lot of devices and equipment, such as safety belt, safety rope, escalator and railing, are needed in this operation, and any of them in poor condition will lead to accident. These devices and equipment are not fully checked against the stipulation of regulations because of the duty negligence or poor safety awareness of safety managers. What's more, the safety problems have been found but not corrected in time, which makes the technical environment in a poor state and the possibility of fall from height increasing.

In the traffic accident, vehicles in hydropower construction projects are special operations vehicles, such as loaders, bulldozers, and trailers. The hydropower construction work space is limited and there are many vehicles in the site at one time, thus, there must be many directional signs and safety signals with good quality to direct the vehicles working. At the same time, the maintenance of vehicles is also very important. But in real construction site, the inadequate supervision results in the failure to provide guidance of vehicles maintenance and to check the qualification of vehicles and to monitor vehicles malfunctions. Therefore, the connection of the factor "inadequate supervision" and factor "technological environment" in traffic accident is strong.

Most hit by objects accidents are caused by the sundries arrangement in mess. This phenomenon is a result of inadequate supervision such as weak oversight of safety supervisors or poor safety education of operators, which makes a passive effect on the technological environment. This will intrude on safety performance in construction site.

The factor "condition of the operator" mainly contains pathological conditions such as medical illness, physical trauma and physical fatigue for individuals. The workers are almost peasant-workers in hydropower construction site, and they were not well educated and trained regularly, thus the personnel quality is not high. However, the psychological and physiological status of workers will be checked regularly to ensure the operators in a good status. If the emotion of workers is disturbed by significant misfortune, they can be found timely and made resignation easily with a casual labor contract. From the Table 8, conditions of the operator are good and this factor has a low accident percentage with 0.043 in fall from height, 0.013 in traffic accident and 0 in hit by objects, respectively.

Different operation types have the same requirements for the operators in the factor "crew resource management". The two factors "planned inappropriate operations" and "supervisory violations" affect the factor "crew resource management", and the relationships are the same in three accident types. The factor "planned inappropriate operations" includes inappropriate assignment of team members or insufficient number of team members or lack of team leaders and poor teamwork. Inappropriate operations could result in unreasonable number of safety mangers in the work team and the safety management could not be implemented effectively. Supervisory violations indicate that the safety mangers are not strict in accordance with the regulations to supervise the team to take pre-shift meetings and predicting potential danger activities.

The two factors, "planned inappropriate operations" and "supervisory violations", also have an association with the factor "personal readiness". Personal readiness involves some causes which are the basic conditions of good operations, such as rest requirements or alcohol restrictions, and these causes can be eliminated by strict examination by safety mangers using regulations.

The causes which lead to accident directly are the four human factors in the first level. The four factors are affected by the same factor "personal readiness", and the relationship is stronger with fall from height than the other accident types. The workers whose status of operation partial determines the construction safety are the most important part in the hydropower construction. At present, the regulations of hydropower construction are more concerned with the operations but little consideration of the off-duty activities. As mentioned above, the hydropower construction has the characteristic with heavy mission and limit time; therefore, the workers often work in three shifts and do not have enough time to rest. When they go into the work space, it is difficult for them to concentrate on the work, making perception errors. On the other hand, the workers are almost peasant-workers with a pretty high turnover, and their operation skills and safety awareness are weak for the reasons that it is difficult for managers to perform safety training or education for them regularly. Besides this, the cultural level of workers is not very high, and the operations are based on the convenient way rather than scientific and systematic construction methods, therefore, habitual violations are common. What's more, when unexpected incidents occur, scientific and effective measures are too lack to decrease the possibility of accident.

Apart from these common relationships, there are also different associations between the factors in the level one and two in three different accident types. In fall from height accident, the factor "perception errors" is also affected by the factor "technological environment" and "crew resource management". The main reason is that the workers are not familiar with technical measures in high-place operation due to the latent human factors, which results in the imbalance or misstep. On the other hand, working in advance, the safety managers fail to identify or report the danger, which results in the workers' unfamiliarity with the physical environment, and then the workers commit perceptual errors. In the traffic accident, the drivers need to obtain the information from physical environment even if the severe environment likes rainy or dark night; it is easy to cause the judging error. 
Based on the above inter-dependence analysis between different factors in three accident types, it is known that the accident is a combined result of many factors. The safety recommendations are provided not only considering the factors themselves but also the interaction of these factors.

\subsection{Safety recommendations}

According to the results of the factors and norms ranking, C5 "personal readiness", B1 “inadequate supervision", and B4 "supervisory violations" are among the first four ranking in all accident types. The D4 "violations" has a higher ranking in fall from height and traffic accident but not in hit by objects whose higher ranking is $\mathrm{C} 1$ "technological environment".

From the Table 9a, it can be found that the most important norm in "personnel readiness" in three accident types is poor safety awareness. Training results includes operation skills, experience, etc. The recommendations for the improvement of safety awareness of the hired personnel focusing on their education and training towards safety operations are applicable to every type of accident. First, the safety awareness, operation skills and experience can be improved by strengthening safety-related education and training with proper supervision. Second, adequate knowledge of safety is an effective way to improve safety awareness. The consciousness and though twill turn into concept, judgments, inference and from a logical and rational thought patterns by education. It is better to form a systematic, highly conscious theoretical system and thought for safety awareness. Lastly, safety culture is essentially important in hydropower construction, we need a steady and sustainable culture of safety training in the field of hydropower construction. By using the safety training, we will lead to improvements in safety awareness during day-to-day operations, with the increases in skill, sensibility, knowledge, and overall competence it provides.

Inadequate supervision and supervisory violations are also very important human factors, and they can affect the personal readiness. From the Table $9 b$, it can be found that "fail to enforce rules and regulations" is the most important norm in supervisory violations for all three accident types. The responsibility of supervisor should be improved by the safety education and training. The requirements of every type of operator should be clarified clearly in the regulations. The assessments of supervisor should be in a quantitative way. The phenomena of absence post and replace post should be strictly prohibited.

From the Table $9 c$, it can be found that the most important norm in "inadequate supervision" in three accident type is insufficient education and training. To offer more suitable and effective education and training, integrated and interactive training system that consists of real-time tracking and data visualization technologies should be established, it can provide real-time feedback to both trainer and trainee so that they can correct their performance immediately on the training site. Engaging all training par- ticipants through data visualization in an immersive virtual reality environment can increase learning effectiveness and keep everyone motivated especially in an increasingly technology-savvy workforce. This system also can be built using Virtual Reality (VR) as a training environment.

From the Table 9d, the norm that operation is not in accordance with the regulations has the highest frequency in both two accident types. The violations mean that the operators do not obey the regulations although the regulations are perfect. Workers' violation behaviors needed to be resolved through more communications between the workers and the managers. The workers should not be assigned to work in extreme working conditions, which often makes trouble for their judgments of failure, prolonged their work time, and forced them to find alternatives that did not comply with the safety rules. The safety awareness of operators should be improved by safety education and training. On the other hand, the supervision must be strengthened. The operations, such as wearing seat belt incorrectly, or spanning the railing, or driving without license, must be identified timely with new technologies.

The technological environment ranked the fourth highest frequency in hit by objects accident. For the objects, such as tools, small materials, which are numerous and in the everywhere of the construction site, the orderly stacking and storage of those objects are very significant, if not, they would be uncontrolled to hit operator. From the Table 9e, it can be found that the highest frequency norm is inadequate safety protection measures. The safety helmet is the basic equipment when workers go into the site and pre-job inspection must be strictly carried out and certified to ensure that the employees wear protective equipment properly. The workers should have a good personnel readiness with good sleeping, good psychological and physiologic condition and without drinking. When crossoperations conduct, special safety supervision should be set and the isolation network need to be set between different construction layers. At last, pre-shift meeting and danger predicting should be carried out to gain a better understanding of construction site.

\section{Conclusions}

The purpose of this work is to determine the importance order of human factors and norms and explore the routes to failure by using frequency statistics and correlation analysis. The human factors are filtered from the 869 accident investigation reports collected from the hydropower enterprises in the year of 1976 to 2017 with HFACS framework. The ranking of human factors and the norms in the first three occurred accidents are given based on the frequency statistics. The methods including Chi-square, lambda and odds ratios are used to analyze the interdependences between the adjacent level factors. The safety recommendations are presented according to the results of this study. 
In our research, the correlation between each factors have been calculated and then find the routes to failure. Compared with some other work (Li et al. 2008; Liu et al. 2013; Zheng et al. 2017), our results has some own characteristics, the similarity level of the path or routes to failure are not very high. In the hydropower construction project, there are many types of engineering accidents with their own characteristics. We find the failure routes of different accident type with higher pertinence, and other research mainly concern on the whole project or industry, such as the aviation and so on. As for specific accident type, the routes may be simple or complex, and this also determined by the operation characteristics. From the results, we can easily find the accidents forming.

This study enhances the understanding of human errors to an important degree. It suggests that the routes which form the failure vary from different accident types. For the same factor or norm, their diversities vary in different accident. In a whole view, the three most important factors are personal readiness, supervisory violations and inadequate supervision. As the inconsistence of route to failure, the accident preventions are taken pertinently. The measures should not only be done for the construction workers but also for all personnel in a construction site.

In order to obtain clear routes without complex structure, we only consider the relationships of factors in the adjacent levels, which is the limitation of HFACS hypothesis.

\section{Acknowledgements}

This work was supported by the National Key Research and Development Program of China (No.2017YFC0805100), the National Natural Science Foundation of China (No. 51379110; 51609128), the Open Foundation of Hubei Key Laboratory of Construction and Management in Hydropower Engineering (No. 2016KSD02).

\section{Disclosure Statement}

The authors declare that they do not have any competing financial, professional, or personal interests from other parties.

\section{References}

Abrams, S.; Wienke, A.; Hens, N. 2017. Modelling time varying heterogeneity in recurrent infection processes: an application to serological data, Journal of the Royal Statistical Society 67(3): 687-704. https://doi.org/10.1111/rssc.12236

Akyuz, E. 2017. A marine accident analysing model to evaluate potential operational causes in cargo ships, Safety Science 92: 17-25. https://doi.org/10.1016/j.ssci.2016.09.010

Baysari, M. T.; Caponecchia, C.; McIntosh, A. S.; Wilson, J. R. 2009. Classification of errors contributing to rail incidents and accidents: A comparison of two human error identification techniques, Safety Science 47: 948-957. https://doi.org/10.1016/j.ssci.2008.09.012
Bentley, T. 2009. The role of latent and active failures in workplace slips, trips and falls: An information processing approach, Applied Ergonomics 40: 175-180. https://doi.org/10.1016/j.apergo.2008.04.009

Bierly, P. E.; Gallagher, S.; Spender, J. C. 2008. Innovation and learning in high-reliability organizations: A case study of United States and Russian Nuclear Attack Submarines, 1970-2000, IEE Transactions on Engineering Management 55: 393-408. https://doi.org/10.1109/TEM.2008.922643

Celik, M.; Cebi, S. 2009. Analytical HFACS for investigating human errors in shipping accidents, Accident Analysis and Prevention 41: 66-75. https://doi.org/10.1016/j.aap.2008.09.004

Chauvin, C.; Lardjane, S.; Morel, G.; Clostermann, J.; Langard, B. 2013. Human and organisational factors in maritime accidents: Analysis of collisions at sea using the HFACS, Accident Analysis and Prevention 59: 26-37.

https://doi.org/10.1016/j.aap.2013.05.006

Chen, T.; Deng, J.; Sitar, N.; Zheng, J.; Liu, T.; Liu, A.; Zheng, L. 2017. Stability investigation and stabilization of a heavily fractured and loosened rock slope during construction of a strategic hydropower station in China, Engineering Geology 221: 70-81. https://doi.org/10.1016/j.enggeo.2017.02.031

Chen, Y.; Chen, M. C. 2011. Using chi-square statistics to measure similarities for text categorization, Expert Systems with Applications 38: 3085-3090.

https://doi.org/10.1016/j.eswa.2010.08.100

Chiu, M. C.; Hsieh, M. C. 2016. Latent human error analysis and efficient improvement strategies by fuzzy TOPSIS in aviation maintenance tasks, Applied Ergonomics 54: 136-147. https://doi.org/10.1016/j.apergo.2015.11.017

Clarke, S.; Ward, K. 2006. The role of leader influence tactics and safety climate in engaging employees' safety participation, Risk Analysis 26: 1175. https://doi.org/10.1111/j.1539-6924.2006.00824.x

Cohen, J. 1960. A coefficient of agreement for nominal scales, Educational and Psychological Measurement 20: 37-46. https://doi.org/10.1177/001316446002000104

Cooper, M. D.; Phillips, R. A. 2004. Exploratory analysis of the safety climate and safety behavior relationship, Journal of Safety Research 35: 497-512.

https://doi.org/10.1016/j.jsr.2004.08.004

Daramola, A. Y. 2014. An investigation of air accidents in Nigeria using the Human Factors Analysis and Classification System (HFACS) framework, Journal of Air Transport Management 35: 39-50. https://doi.org/10.1016/j.jairtraman.2013.11.004

Dekker, S. W. A. 2001. The reinvention of human error, Human Factors \& Aerospace Safety 1: 1153-1155.

Dekker, S. W. 2002. Reconstructing human contributions to accidents: the new view on error and performance, Journal of Safety Research 33: 371-385.

https://doi.org/10.1016/S0022-4375(02)00032-4

Ergai, A.; Cohen, T.; Sharp, J.; Wiegmann, D.; Gramopadhye, A.; Shappell, S. 2016. Assessment of the human factors analysis and classification system (HFACS): Intra-rater and inter-rater reliability, Safety Science 82: 393-398. https://doi.org/10.1016/j.ssci.2015.09.028

Fang, D.; Chen, S.; Chen, B. 2015. Emergy analysis for the upper Mekong River intercepted by the Manwan hydropower construction, Renewable \& Sustainable Energy Reviews 51: 899-909. https://doi.org/10.1016/j.rser.2015.06.061

Goodman, L. A.; Kruskal, W. H. 1954. Measures of association for cross classifications, Journal of The American Statistical Association 49: 732-764. 
Haslam, R. A.; Hide, S. A.; Gibb, A.; Gyi, D. E.; Pavitt, T.; Atkinson, S.; Duff, A. R. 2005. Contributing factors in construction accidents, Applied Ergonomics 36: 401-415. https://doi.org/10.1016/j.apergo.2004.12.002

Heinrich, H. W. 1931. Industrial accident prevention: A scientific approach. McGraw-Hill.

Jia, N.; Xie, M.; Chai, X. 2012. Development and implementation of a GIS-based safety monitoring system for hydropower station construction, Journal of Computing in Civil Engineering 26: $44-53$.

https://doi.org/10.1061/(ASCE)CP.1943-5487.0000105

Jiang, H.; Lin, P.; Fan, Q.; Qiang, M. 2014. Real-time safety risk assessment based on a real-time location system for hydropower construction sites, The Scientific World Journal. Article ID 235970. https://doi.org/10.1155/2014/235970

Koirala, S.; Hill, D.; Morgan, R. 2017. Impacts of the delay in construction of a large scale hydropower project on potential displaces, Impact Assessment \& Project Appraisal 35: 106-116. https://doi.org/10.1080/14615517.2016.1271540

Lenne, M. G.; Salmon, P. M.; Liu, C. C.; Trotter, M. 2012. A systems approach to accident causation in mining: An application of the HFACS method, Accident Analysis and Prevention 48: 111-117. https://doi.org/10.1016/j.aap.2011.05.026

Li, W. C.; Harris, D.; Yu, C. S. 2008. Routes to failure: analysis of 41 civil aviation accidents from the Republic of China using the human factors analysis and classification system, Accident Analysis \& Prevention 40: 426-434.

https://doi.org/10.1016/j.aap.2007.07.011

Liu, S. Y.; Chi, C. F.; Li, W. C. 2013. The application of human factors analysis and classification system (HFACS) to investigate human errors in helicopter accidents, Lecture Notes in Computer Science 8020: 85-94. https://doi.org/10.1007/978-3-642-39354-9_10

Liu, T. H.; Zhong, M. H.; Xing, J. 2005. Industrial accidents: Challenges for China's economic and social development, Safety Science 43: 503-522.

https://doi.org/10.1016/j.ssci.2005.08.012

Liu, Z.; Xu, W.; Zhai, X.; Qian, C.; Chen, X. 2017. Feasibility and performance study of the hybrid ground-source heat pump system for one office building in Chinese heating dominated areas, Renewable Energy 101: 1131-1140. https://doi.org/10.1016/j.renene.2016.10.006

Madigan, R.; Golightly, D.; Madders, R. 2016. Application of human factors analysis and classification system (HFACS) to UK rail safety of the line incidents, Accident Analysis and Prevention 97: 122-131. https://doi.org/10.1016/j.aap.2016.08.023

Masirevic, D. J. 2017. On new formulas for the cumulative distribution function of the noncentral Chi-Square distribution, Mediterranean Journal of Mathematics 14: 383-384.

Moura, M. C.; Azevedo, R. V.; Droguett, E. L.; Rego, L. C.; Lins, I. D.; Vilela, R. F.; Sales Filho, R. 2016. Estimation of expected number of accidents and workforce unavailability through Bayesian population variability analysis and Markovbased model, Reliability Engineering \& System Safety 154: 234. https://doi.org/10.1016/j.ress.2016.07.005

Olsen, N. S. 2014. Coding ATC incident data using HFACS: Inter-coder consensus, Safety Science 49(10): 1365-1370. https://doi.org/10.1016/j.ssci.2011.05.007

Olsen, N. S.; Shorrock, S. T. 2010. Evaluation of the HFACSADF safety classification system: Inter-coder consensus and intra-coder consistency, Accident Analysis and Prevention 42: 437-444. https://doi.org/10.1016/j.aap.2009.09.005
Patterson, J. M.; Shappell, S. A. 2010. Operator error and system deficiencies: Analysis of 508 mining incidents and accidents from Queensland, Australia using HFACS, Accident Analysis and Prevention 42: 1379-1385.

https://doi.org/10.1016/j.aap.2010.02.018

Reason, J. 2000. Human error, Western Journal of Medicine 172(6): 393-396. https://doi.org/10.1017/CBO9781139062367

Roscoe, J. T.; Byars, J. A. 1971. An investigation of the restraints with respect to sample size commonly imposed on the use of the Chi-square statistic, Journal of The American Statistical Association 66: 755-759. https://doi.org/10.1080/01621459.1971.10482341

Shappell, S. A.; Wiegmann, D. A. 2001. Applying reason: The human factors analysis and classification system (HFACS), Gastroenterology Research 1: 207-212.

Shappell, S.; Detwiler, C.; Holcomb, K.; Hackworth, C.; Boquet, A.; Wiegmann, D. A. 2007. Human error and commercial aviation accidents: An analysis using the human factors analysis and classification system, Human Factors 49: 227242. https://doi.org/10.1518/001872007X312469

Suraji, A.; Duff, A. R.; Peckitt, S. J. 2001. Development of causal model of construction accident causation, Journal of Construction Engineering and Management 127: 337-344. https://doi.org/10.1061/(ASCE)0733-9364(2001)127:4(337)

Tamborello, F. P. I.; Trafton, J. G. 2017. Human error as an emergent property of action selection and task place-holding, Human Factors 59: 377-392. https://doi.org/10.1177/0018720816672529

Tvaryanas, A. P.; Thompson, W. T.; Constable, S. H. 2006. Human factors in remotely piloted aircraft operations: HFACS analysis of 221 mishaps over 10 years, Aviation Space and Environmental Medicine 77: 724-732.

Wang, W.; Albert, J. M. 2017. Causal mediation analysis for the Cox proportional hazards model with a smooth baseline hazard estimator, Journal of the Royal Statistical Society 66(4): 741-757. https://doi.org/10.1111/rssc. 12188

Wiegmann, D. A.; Shappell, S. A. 2003. A human error approach to aviation accident analysis: The human factors analysis and classification system. Routledge.

Zhan, Q.; Zheng, W.; Zhao, B. 2017. A hybrid human and organizational analysis method for railway accidents based on HFACS-Railway Accidents (HFACS-RAs), Safety Science 91: 232-250. https://doi.org/10.1016/j.ssci.2016.08.017

Zheng, X. Z.; Wang, F.; Zhou, J. L. 2017. A hybrid approach for evaluating faulty behavior risk of high-risk operations using ANP and evidence theory, Mathematical Problems in Engineering, Article ID 7908737. https://doi.org/10.1155/2017/7908737

Zhou, J.-L.; Bai, Z.; Sun, Z. 2014. A hybrid approach for safety assessment in high-risk hydropower-construction-project work systems, Safety Science 64: 163-172. https://doi.org/10.1016/j.ssci.2013.12.008

Zhou, J.-L.; Lei, Y. 2017. Paths between latent and active errors: Analysis of 407 railway accidents/incidents' causes in China, Safety Science. In Press. https://doi.org/10.1016/j.ssci.2017.12.027 